\title{
Expression of thymidine phosphorylase and VEGF in esophageal squamous cell carcinoma
}

\author{
TAKUMA NOMIYA, KENJI NEMOTO, EIKO NAKATA, YOSHIHIRO TAKAI and SHOGO YAMADA
}

\author{
Department of Radiation Oncology, Tohoku University Hospital, Sendai 980-8574, Japan
}

Received February 22, 2006; Accepted March 25, 2006

\begin{abstract}
The purpose of this study was to determine the role of TP and VEGF in angiogenesis and its clinical significance in prognosis of patients with esophageal carcinoma. Expressions of TP and VEGF, microvascular density and cell proliferation activity were evaluated by using 40 immunohistochemically stained resected esophageal carcinoma tissues, and the survival rate of the patients was analyzed. Significant positive correlation and regression were found between the VEGF expression level of tumor and microvascular density $(\mathrm{r}=0.73, \mathrm{p}<0.0001)$. Not statistically strong but significant positive correlation and regression were found between the TP expression level of tumor and microvascular density $(\mathrm{r}=0.32, \mathrm{p}=0.046)$. No significant relationships were found between TP and VEGF expressions. Pathological T-factor and pathological $\mathrm{N}$-factor were significant prognostic factors. Tumor length, site of lesion, gender, age, and Ki67 labeling index were not significant prognostic factors. The VEGF expression level was one of the unfavorable prognostic factors (risk ratio $=1.035,95 \% \mathrm{CI}=1.007-1.065, \mathrm{p}=0.01$ ). The patients with high TP expression showed a tendency for unfavorable prognosis, but it was not statistically significant ( $\mathrm{RR}=1.017,95 \% \mathrm{CI}=0.996-1.042, \mathrm{p}=0.1$ ). The prognosis of patients in the TP/VEGF[+/+] group was significantly poorer than that of the patients in the TP/ VEGF[-/-] group and TP/VEGF[+/- or $-/+]$ group $(\mathrm{RR}=0.488$ for TP/VEGF[-/-] group, $=0.717$ for TP/VEGF $[+/-$ or $-/+]$ group, $\mathrm{p}=0.005)$. In conclusion, VEGF and TP expression seems to have a relationship with tumor angiogenesis, and co-expression of TP and VEGF seemed to be one of the unfavorable prognostic factors.
\end{abstract}

\section{Introduction}

Thymidine phosphorylase (TP) is identical to platelet-derived endothelial cell growth factor (PD-ECGF) and is an enzyme of $\sim 55 \mathrm{kDa}$ in molecular weight (1-7). TP catalyzes the

Correspondence to: Dr Takuma Nomiya, Department of Radiology, Tohoku University Hospital, 1-1, Seiryo-machi, Aobaku, Sendai 980-8574, Japan

E-mail: nomiya@rad.med.tohoku.ac.jp

Key words: thymidine phosphorylase, esophageal carcinoma, microvascular density, VEGF, angiogenesis reversible conversion of dThd and phosphate to thymine and 2-deoxyribose-1-phosphate, and several studies have suggested that TP increases cellular uptake of [methyl- $\left.{ }^{3} \mathrm{H}\right]-$ thymidine (3-5). It is also known that TP has an important role in tumor growth, but several studies have revealed that TP does not have a direct effect on cell proliferative activity (4-6,8-11). Much interest has recently been shown in the angiogenetic activity of TP that is due to thymidine metabolism and migration of endothelial cells (5-8). It has also been reported that intra-tumoral angiogenesis, VEGF expression level, and microvascular density correlate with prognosis of patients with various malignancies (11-15).

The aim of the present study was to determine the relationships between intra-tumoral TP expression, VEGF expression, and microvascular density and to determine the significance of TP and VEGF expressions in patients with esophageal carcinoma.

\section{Materials and methods}

Patients. Forty surgically resected esophageal squamous cell carcinoma tissues with good quality material remaining were stained for TP, VEGF, CD34 and Ki67 by immunohistochemistry. The samples were obtained from patients with esophageal carcinoma who had undergone esophagectomy at our hospital in the period from January 1988 to April 1998. None of the patients had undergone either preoperative irradiation or preoperative chemotherapy and none of them had synchronous malignancy of another site.

\section{Immunohistochemistry}

CD34 (specific antibody for endothelial cells). Paraffinembedded tissue was cut into $3-\mu \mathrm{m}$-thick sections and mounted on slides. Sections were deparaffinized and rehydrated. Endogenous peroxidase was blocked by $0.3 \%$ perhydrase methanol for $30 \mathrm{~min}$ followed by washing in distilled water. Sections in $0.01 \mathrm{M}$ citrate buffer were heated in a microwave for $5 \mathrm{~min}$. After washing in distilled water, the sections were washed in $0.01 \mathrm{M}$ PBS 3 times for 5 min each time. Nonspecific reactions were prevented by pretreatment with $1 \%$ normal rabbit serum. The antibody against CD34 (Nichirei Inc., Tokyo, Japan) was diluted 1:50 and incubated overnight. The sections were then washed 3 times for 5 min each time in PBS, incubated for $10 \mathrm{~min}$ in pre-formed streptavidinbiotinylated peroxidase complex (Dako LSAB kit, Dako Japan), slightly counterstained with Mayer's hematoxylin, dehydrated, cleared, and mounted. 
Table I. Characteristics and clinical parameters of the patients.

Patient characteristics

\begin{tabular}{|c|c|c|}
\hline Number of patients & Total & 40 \\
\hline Age & $($ Mean \pm SD $)$ & $65.8 \pm 7.3$ \\
\hline \multirow[t]{2}{*}{ Gender } & Male & 36 \\
\hline & Female & 4 \\
\hline Histology & Squamous cell carcinoma & 40 \\
\hline Clinical stage & $\mathrm{I}$ & 4 \\
\hline \multirow[t]{2}{*}{ (UICC 5th edition) } & II & 15 \\
\hline & III & 21 \\
\hline \multirow{4}{*}{$\begin{array}{l}\text { Depth of invasion } \\
\text { (pathological T-factor) }\end{array}$} & Submucosa (pT1) & 6 \\
\hline & Muscularis propria (pT2) & 5 \\
\hline & Adventitia (pT3) & 25 \\
\hline & Adjascent structures (pT4) & 4 \\
\hline Lymph node metastasis & Negative (pN0) & 10 \\
\hline (pathological N-factor) & Positive (pN1) & 30 \\
\hline \multirow[t]{4}{*}{ Tumor length (mm) } & $20-40$ & 10 \\
\hline & $40-60$ & 18 \\
\hline & $60-80$ & 6 \\
\hline & $80-100$ & 6 \\
\hline \multirow[t]{3}{*}{ Site of lesion } & Upper thoracic esophagus & 6 \\
\hline & Middle thoracic esophagus & 18 \\
\hline & Lower thoracic esophagus & 16 \\
\hline
\end{tabular}

TP (thymidine phosphorylase). The antibody against TP (murine anti-human TP monoclonal antibody 1C6-203, Roche Laboratory, Kamakura, Japan) was diluted 1:50 and incubated at $4{ }^{\circ} \mathrm{C}$ overnight. An esophageal tumor that showed intense positivity for TP was used as a positive control. As a negative control, a section from each sample was processed without the first antibody. The procedure used for immunohistochemical staining (cutting, deparaffinization, and rehydration) was similar to the staining method used for CD34 except for the antibody.

VEGF (vascular endothelial cell growth factor). An antibody against human VEGF (Santa Cruz Biotechnology Inc., CA, USA) was diluted 1:20 and incubated at $4^{\circ} \mathrm{C}$ overnight.

Ki67 (index of cell proliferation activity). An antibody against Ki67 protein, clone MIB-1 (Immunotech, Marseilles, France), was diluted 1:300 and incubated at $4^{\circ} \mathrm{C}$ overnight.

\section{Evaluation}

Microvascular density (MVD). MVD was estimated as an index of the most active neovascularization in the tumor. Using sections stained with anti-CD34 antibody, microvessel counts were made in a $\times 200$ field with the highest neovascularization. Microvessels were counted using the methods described by Weidner (16).

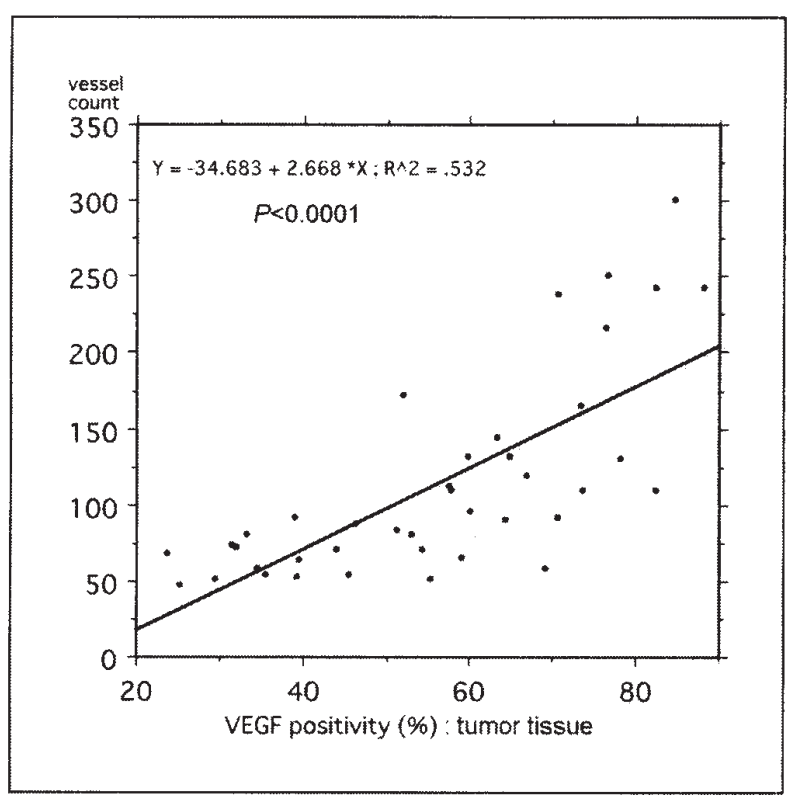

Figure 1. Correlation between microvascular density and VEGF-positive cell rate: $\mathrm{x}$-axis shows VEGF expression score and $\mathrm{y}$-axis shows microvascular density. Significant correlation and regression are shown between these parameters $(r=0.73, \mathrm{p}<0.0001)$.

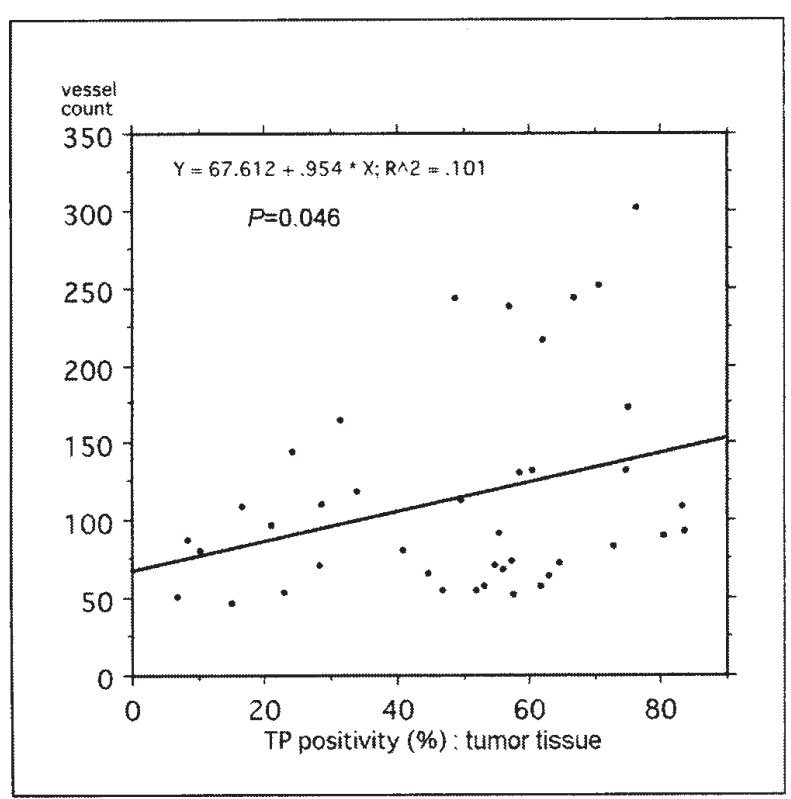

Figure 2. Correlation between microvascular density and TP-positive cell rate. Significant but not strong correlation and regression are shown between these parameters $(\mathrm{r}=0.32, \mathrm{p}=0.046)$.

TP expression and VEGF expression. The expression of TP and VEGF was microscopically evaluated at a magnification of $\mathrm{x} 200$. Several microscopic fields were selected at random, and the TP-positive cell rate or VEGF-positive cell rate was calculated by counting 1000 malignant cells.

Ki67 labeling index (Ki67-LI). The Ki67 antibody com-bines with a nuclear antigen that is present in proliferating cells but absent in resting cells. Several microscopic fields were selected 


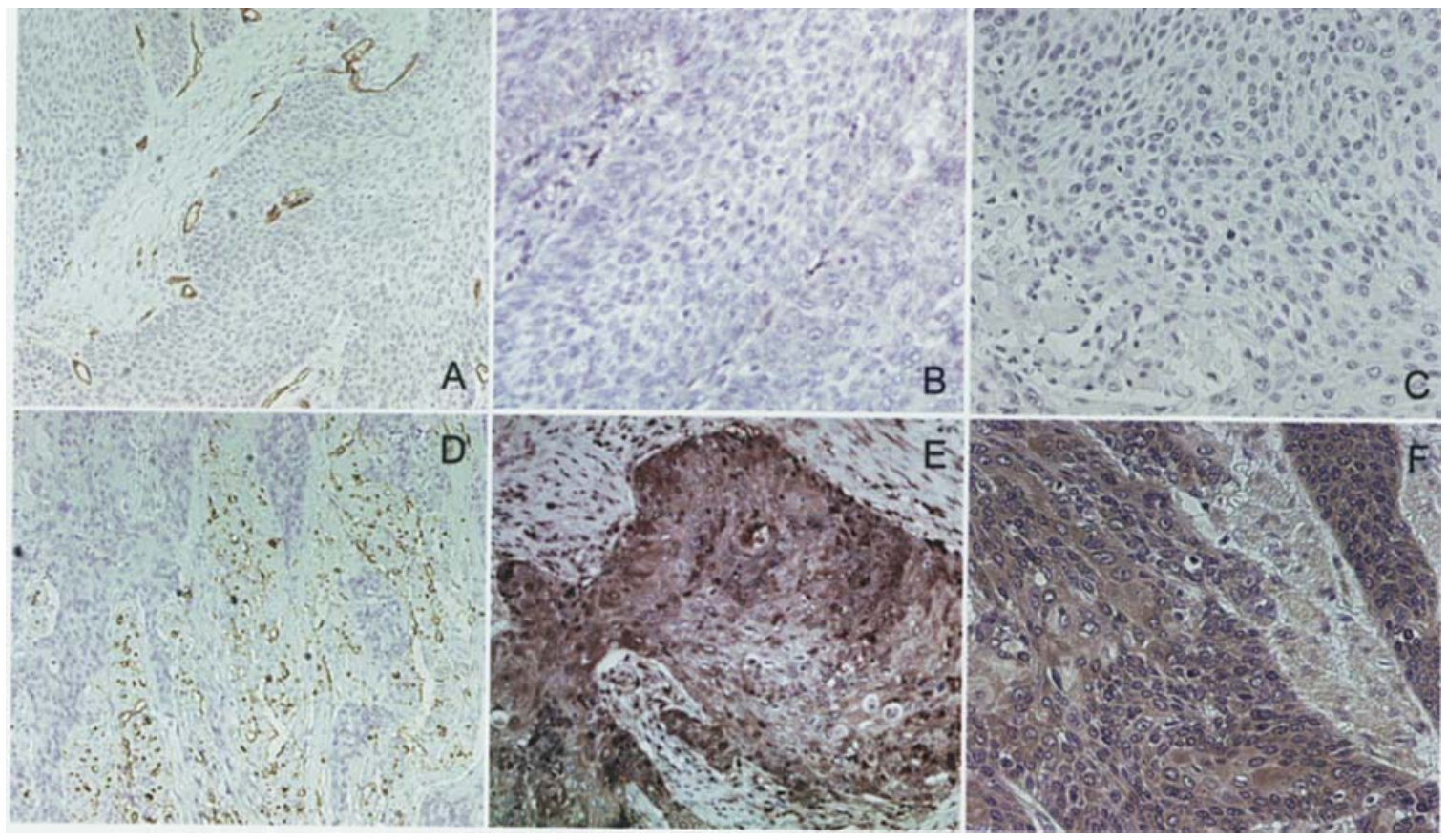

Figure 3. Microscopic findings of typical cases in the low TP/VEGF expression group and the high TP/VEGF expression group. (A-C) and (D-F) are different stain of the same cases, respectively. (A and B) Immunohistochemically stained for CD34 with a magnification of x200. (B and E) Immunohistochemically stained for TP with a magnification of $\mathrm{x} 400$. (C and F) Immunohistochemically stained for VEGF with a magnification of $\mathrm{x} 400$.

at random, and the Ki67-positive cell rate (Ki67-LI) was calculated by counting 1000 malignant cells.

Statistical analysis. The TP-positive cell rate, VEGF-positive cell rate, and Ki67 labeling index were analyzed by the unpaired t-test, Mann-Whitney U test, and Spearman's rank correlation. The Cox's proportional hazards model, the KaplanMeier method and log-rank test were used for survival analysis.

\section{Results}

TP/VEGF expression and microvascular density. Patient characteristics are shown in Table I. In the analysis of VEGF expression, patients were divided into two groups of equal size according to VEGF expression. Microvascular density of high VEGF expression group $(n=20)$ was significantly higher than that of low VEGF expression group $(n=20$; microvascular density [mean $\pm \mathrm{SD}$ ]: $153 \pm 71$ vs. $76 \pm 28, \mathrm{p}<0.0001)$. Fig. 1 shows the correlation between microvascular density and VEGF-positive cell rate in tumor tissue. Significant positive correlation and regression were found between microvascular density and VEGF-positive cell rate $(r=0.73$ : $p<0.0001)$. Ki67 labeling index of high VEGF expression group was significantly lower than that of low VEGF expression group $(\mathrm{p}=0.01)$. According to our previous study, this low cell proliferation activity and high VEGF expression seemed to be due to the presence of hypoxic fraction in tumor tissue (17). No significant relationship was found between VEGF positivity and other factors.

In the analysis of TP expression, microvascular density of high TP expression group ( $\mathrm{n}=20$ ) was borderline significantly higher than that of low TP expression group $(n=20$; micro- vascular density: $134 \pm 76$ vs. $95 \pm 48, p=0.055)$. Fig. 2 shows the correlation between microvascular density and TP-positive cell rate in tumor tissue. Significant positive correlation and regression were found between microvascular density and TP-positive cell rate $(\mathrm{r}=0.32, \mathrm{p}=0.046)$, but the correlation between TP expression and microvascular density was not statistically stronger than that between VEGF expression and microvascular density. No significant relationship was found between TP positivity and VEGF positivity of tumor tissue. No significant relationships was found between TP positivity and other factors.

Fig. 3 shows microscopic findings of typical cases in the low TP/VEGF expression group and the high TP/VEGF expression group. Fig. $3 \mathrm{~A}-\mathrm{C}$ are the same cases in the low TP/VEGF expression group and Fig. 3D-F are the same cases in the high TP/VEGF expression group (A and D: CD34 stain, B and E: TP stain, C and F: VEGF stain). In the typical case of low TP/VEGF expression group (Fig. 3A-C), there were few TP-positive cells and VEGF-positive cells in the specimen (Fig. 3B and C), and there were few microvessels in the field (Fig. 3A). In the typical case of high TP/VEGF expression group (Fig. 3D-F), on the other hand, there were many TP-positive cells and VEGF-positive cells in the tumor tissue (Fig. 3E and F) and well-developed microvessels were found in both the tumor and stromal tissue (Fig. 3D). These results suggest that VEGF and TP contribute to tumor neovascularization, and the difference in statistical significance seems to be caused by a difference in the biochemical potential of angiogenesis.

Survival analyses. Twenty-one cases of death were observed and 19 cases were alive at the final follow-up date. Median follow-up period of all patients was 22.3 months. The deaths 


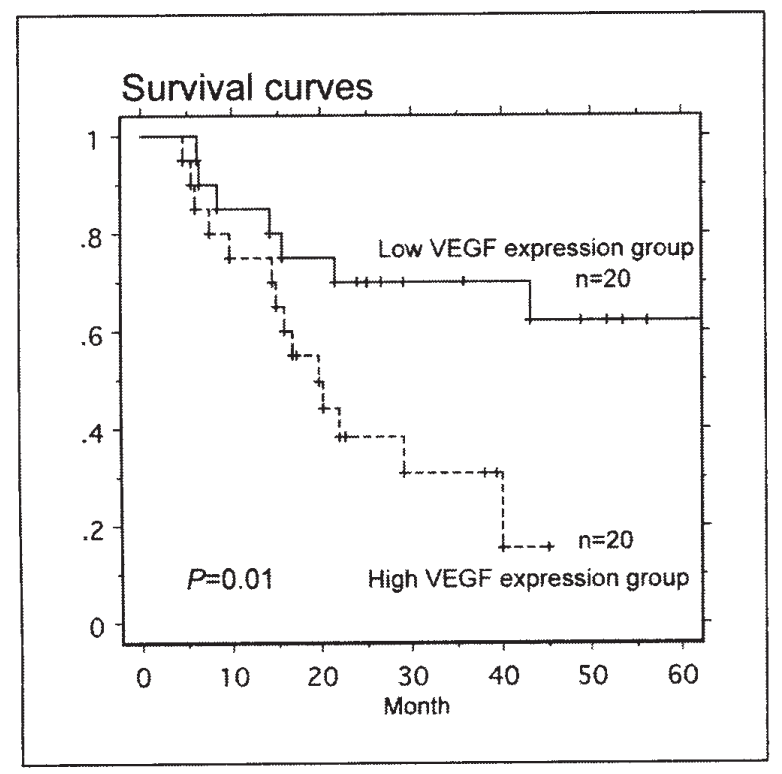

Figure 4. Survival curves according to VEGF expression. The patients with high VEGF positivity showed unfavorable prognosis $(\mathrm{p}=0.01)$.

were caused by primary disease, and there was no intercurrent death. In the Cox proportional hazards model, the pathological $\mathrm{T}$-factor and the pathological $\mathrm{N}$-factor were significant prognostic factors $(\mathrm{p}<0.001, \mathrm{p}=0.02$, respectively). In the analysis of parameters other than TNM factors, site of lesion, tumor length, gender, age, and Ki67 labeling index were not significant prognostic factors. The VEGF positivity of tumor was one of the significant prognostic factors (risk ratio $[R R]=1.035,95 \% \mathrm{CI}=1.007-1.065, \mathrm{p}=0.01)$. The patients were divided into two groups of equal size according to intratumoral VEGF-positive cell rate (high VEGF expression group: $n=20$, low VEGF expression group: $n=20$, median 57.5\%). Fig. 4 shows the survival curves according to VEGF-positive cell rate. Three-year survival rates of the low VEGF expression group and high VEGF expression group were 70 and $31 \%$, respectively. The prognosis of patients in the high VEGF expression group was significantly more unfavorable than that of patients in the low VEGF expression group. The TP-positive cell rate of the tumors showed a tendency for unfavorable prognosis, but it was not statistially significant $(\mathrm{RR}=1.017,95 \% \mathrm{CI}=0.996-1.042$, $\mathrm{p}=0.1$ ). In the survival analysis according to TP expression (high TP expression group: $\mathrm{n}=20$, low TP expression group: $\mathrm{n}=20$, median $54.9 \%$ ), 3-year survival rates of the low TP expression group and high TP expression group were 62 and $40 \%$, respectively.

The patients were divided into 3 groups according to the combination of intra-tumoral VEGF expression and TP expression: TP/VEGF[-/-] group (patients with low TP expression and low VEGF expression: $n=11$ ), TP/VEGF[+/- or $-/+]$ group (patients with low TP expression and high VEGF expression or patients with high TP expression and low VEGF expression: $n=18$ ), TP/VEGF[+/+] group (patients with high TP expression and high VEGF expression group: $\mathrm{n}=11$ ). Fig. 5 shows survival curves according to TP/VEGF expression. Three-year survival rates of the TP/VEGF[-/-] group, TP/VEGF[+/- or -/+] group, and TP/VEGF[+/+]

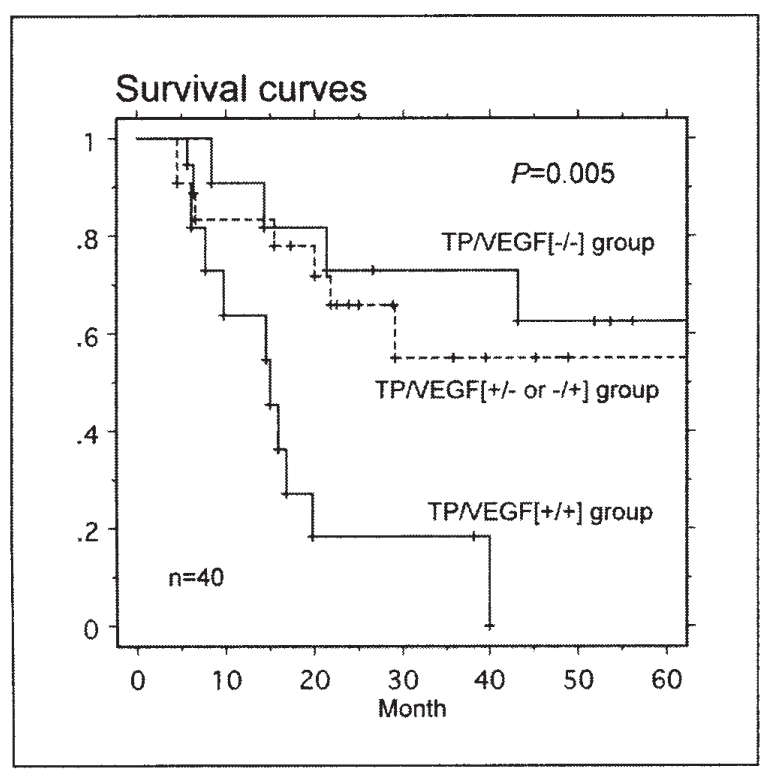

Figure 5. Survival curves according to TP and VEGF expressions: TP/VEGF[-/-]: $n=11$; TP/VEGF[+/- or -/+]: $n=18$; TP/VEGF[+/+]: $n=11$. $\mathrm{TP} / \mathrm{VEGF}[+/+]$ group showed poorer prognosis than the other groups $(\mathrm{p}=0.005)$.

group were 73,55 , and $18 \%$, respectively $(\mathrm{RR}=0.488$ for TP/VEGF[-/-] group, $=0.717$ for TP/VEGF[+/- or $-/+]$ group, $\mathrm{p}=0.005)$. The prognosis of patients in the TP/VEGF $[+/+]$ group was much worse than that of patients in the other groups, and the prognosis of patients in the TP/VEGF[-/-] group was significantly better than that of patients in the other groups.

\section{Discussion}

Analysis of microvascular density in this study showed significant correlations between microvascular density and VEGF-positive cell rate and TP-positive cell rate (Figs. 1 and 2). Correlations between TP expression and microvascular density in various malignancies have been found in several studies $(11-15,18,19)$, agreeing with the results of the present study. No significant relationship was found by analysis of Ki67 LI and TP expression in this study. It has been suggested that TP itself is not a growth factor and does not have a direct effect of cell proliferation $(4,6)$.

A positive correlation between TP expression and microvascular density was found (Fig. 2), but this positive correlation was not as strong as that between VEGF expression and microvascular density. Although a direct comparison of the activities of VEGF and TP was not made, the difference in these results suggests the potential of angiogenesis of TP and VEGF.

Many authors have reported that malignant tumors show overexpression of TP compared to the expression in normal tissues $(6,8,10-13,18-21)$. It has also been shown in many studies that TP overexpression is one of the unfavorable prognostic factors $(11-14,18,22-24)$. We analyzed prognoses of patients according to expressions of TP and VEGF in the present study, and we found that the prognosis of patients in the TP/VEGF[-/-] group was significantly more favorable and that the prognosis of patients in the TP/VEGF $[+/+]$ group was significantly poorer (Fig. 5). 
The cases of death in this study showed distant metastases soon after the start of treatment. Some studies have suggested correlations of TP overexpression with lymphatic invasion and venous invasion of tumor cells $(11,14)$, and the occurrence of hematogenous and/or lymphogenous metastases due to well-developed neovascularization is therefore thought to be one of the causes of unfavorable prognosis. Several investigators have also suggested that co-expression of TP and VEGF is a clinically unfavorable prognostic factor in some malignancies $(13,22)$.

One of the functions of TP is the catalysis of 5'-deoxy-5fluorouridine (5'-DFUR) to 5-FU (25). It is therefore thought that an anticancer drug is more effective in tumors that have high expression levels of TP, due to efficient reaction of 5'DFUR to 5-FU, than in tumors with low TP expression levels. Several clinical and experimental studies have shown the outcomes of anticancer treatment using 5 -FU or its precursor $(7,23,25,26)$.

In conclusion, TP facilitates tumor neovascularization and it is one of the unfavorable prognostic factors in various malignancies, including esophageal carcinoma. On the other hand, expression of TP enhances the effect of some anticancer drugs by enhancing catalysis of 5-FU prodrugs.

Based on the results, it is thought that evaluation of TP and VEGF expressions is useful for estimating prognosis of patients and for selecting an optimal anticancer drug for treatment of patients with esophageal carcinoma.

\section{References}

1. Furukawa T, Yoshimura A, Sumizawa T, et al: Angiogenic factor. Nature 356: 668, 1992

2. Hotchkiss KA, Ashton AW, Klein RS, Lenzi ML, Zhu GH and Schwartz EL: Mechanisms by which tumor cells and monocytes expressing the angiogenic factor thymidine phosphorylase mediate human endothelial cell migration. Cancer Res 63: $527-533,2003$.

3. Sumizawa T, Furukawa T, Haraguchi M, et al: Thymidine phosphorylase activity associated with platelet-derived endothelial cell growth factor. Biochem (Tokyo) 114: 9-14, 1993.

4. Moghaddam A and Bicknell R: Expression of platelet-derived endothelial cell growth factor in Escherichia coli and confirmation of its thymidine phosphorylase activity. Biochemistry 31: 12141-12146, 1992.

5. Finnis C, Dodsworth N, Pollitt CE, Carr G and Sleep D: Thymidine phosphorylase activity of platelet-derived endothelial cell growth factor is responsible for endothelial cell mitogenicity. Eur J Biochem 212: 201-210, 1993.

6. Moghaddam A, Zhang HT, Fan TP, et al: Thymidine phosphorylase is angiogenic and promotes tumor growth. Proc Natl Acad Sci USA 92: 998-1002, 1995.

7. Ogura O, Kanzaki A, Bando H, Ogura T, Toi M and Takebayashi Y: Expression of thymidylate synthase and thymidine phosphorylase in human breast carcinoma: implication for method to detect expression of these molecules in clinic. Cancer Lett 190: 97-104, 2003.

8. Luccioni C, Beaumatin J, Bardot V and LeFrancois D: Pyrimidine nucleotide metabolism in human colon carcinomas: comparison of normal tissues, primary tumors and xenografts. Int J Cancer 58: 517-522, 1994.
9. Fukuiwa T, Takebayashi Y, Akiba S, et al: Expression of thymidine phosphorylase and vascular endothelial cell growth factor in human head and neck squamous cell carcinoma and their different characteristics. Cancer 85: 960-969, 1999.

10. Takebayashi Y, Yamada K, Miyadera K, et al: The activity and expression of thymidine phosphorylase in human solid tumours. Eur J Cancer 32A: 1227-1232, 1996.

11. Takebayashi Y, Miyadera K, Akiyama S, et al: Expression of thymidine phosphorylase in human gastric carcinoma. Jpn J Cancer Res 87: 288-295, 1996.

12. Imazano Y, Takebayashi Y, Nishiyama K, et al: Correlation between thymidine phosphorylase expression and prognosis in human renal cell carcinoma. J Clin Oncol 15: 2570-2578, 1997.

13. Tsujitani S, Saito H, Maeta Y, et al: Neoangiogenesis in patients with gastric carcinoma in relation to the expression of vascular endothelial growth factor and thymidine phosphorylase. Anticancer Res 24: 1853-1859, 2004.

14. Takebayashi Y, Akiyama S, Akiba S, et al: Clinicopathologic and prognostic significance of an angiogenic factor, thymidine phosphorylase, in human colorectal carcinoma. J Natl Cancer Inst 88: 1110-1117, 1996.

15. Toi M, Hoshina S, Taniguchi T, Yamamoto Y, Ishitsuka H and Tominaga T: Expression of platelet-derived endothelial cell growth factor/thymidine phosphorylase in human breast cancer. Int J Cancer 64: 79-82, 1995.

16. Weidner N: Current pathologic methods for measuring intratumoral microvessel density within breast carcinoma and other solid tumors: Breast Cancer Res Treat 36: 169-180, 1995.

17. Nomiya T, Nemoto K, Yamada S, et al: Relationships between radiosensitivity and microvascular density in esophageal carcinoma: significance of hypoxic fraction. Int J Radiat Oncol Biol Phys 58: 589-596, 2004.

18. Takebayashi Y, Natsugoe S, Baba M, et al: Thymidine phosphorylase in human esophageal squamous cell carcinoma. Cancer 85: 282-289, 1999.

19. Morinaga S, Yamamoto Y, Noguchi Y, et al: Platelet-derived endothelial cell growth factor (PD-ECGF) is up-regulated in human hepatocellular carcinoma (HCC) and the corresponding hepatitis liver. Atogastroenterology 50: 1521-1526, 2003.

20. O'Brien TS, Fox SB, Dickinson AJ, et al: Expression of the angiogenic factor thymidine phosphorylase/platelet-derived endothelial cell growth factor in primary bladder cancers. Cancer Res 56: 4799-4804, 1996.

21. Giatromanolaki A, Koukourakis MI, Comley M, et al: Plateletderived endothelial cell growth factor (thymidine phosphorylase) expression in lung cancer. J Pathol 181: 196-199, 1997.

22. Toi M, Gion M, Biganzoli E, et al: Co-determination of the angiogenic factors thymidine phosphorylase and vascular endothelial growth factor in node-negative breast cancer: prognostic implications. Angiogenesis 1: 71-83, 1997.

23. Yamaue $\mathrm{H}$, Tanimura $\mathrm{H}$, Kono $\mathrm{N}$, et al: Clinical efficacy of doxifluridine and correlation to in vitro sensitivity of anticancer drugs in patients with colorectal cancer. Anticancer Res 23: 2559-2564, 2003.

24. Ryu SY, Oka K, Tsujii H, Suzuki Y and Nakano T: Plateletderived endothelial cell growth factor as a prognostic factor for radiotherapy outcome in patients with adenocarcinoma of the uterine cervix. Gynecol Oncol 89: 414-419, 2003.

25. Patterson AV, Zhang H, Moghaddam A, et al: Increased sensitivity to the prodrug 5'-deoxy-5-fluorouridine and modulation of 5-fluoro-2'-deoxyuridine sensitivity in MCF-7 cells transfected with thymidine phosphorylase. Br J Cancer 72: 669-675, 1995.

26. Haraguchi M, Furukawa T, Sumizawa T and Akiyama S: Sensitivity of human KB cells expressing platelet-derived endothelial cell growth factor to pyrimidine antimetabolites. Cancer Res 53: 5680-5682, 1993. 